\title{
Effect of sulphonated polyethersulfone substrate for thin film composite forward osmosis membrane
}

\author{
Soleyman Sahebi ${ }^{1}$, Sherub Phuntsho ${ }^{1}$, Yun Chul Woo ${ }^{1}$, Myoung Jun Park ${ }^{1}$, Leonard D. Tijing ${ }^{1}$, \\ Seungkwan Hong ${ }^{2}$, Ho Kyong Shon ${ }^{1, *}$
}

${ }^{1}$ Centre for Technology in Water and Wastewater, School of Civil and Environmental Engineering, University of Technology Sydney (UTS), P.O. Box 123, 15 Broadway, NSW 2007, Australia.

${ }^{2}$ School of Civil, Environmental \& Architectural Engineering, Korea University, 1-5 Ga, Anam-Dong, Seongbuk-Gu, Seoul, 136-713, Republic of Korea

* Corresponding author: Email: Hokyong.Shon-1@uts.edu.au

\begin{abstract}
Sulphonated polyethersulfone (SPES) has been synthesized for developing high performance thin film composite (TFC) forward osmosis (FO) membranes with enhanced hydrophilic support layer. Sulphonated substrate not only affects the membrane performance but also changes the membrane morphology from finger-like structure to a sponge-like morphology at higher degree of sulphonation thereby affecting the mechanical strength of the FO membrane. Non-sulphonated TFC-FO membrane with 12 wt $\%$ polymer concentration shows a faint finger-like structure while sulphonated samples at a similar polymer concentration show a fully sponge-like structure with much higher performance. For example, a water flux of 35 $\mathrm{Lm}^{-2} \mathrm{~h}^{-1}$ and $0.28 \mathrm{gL}^{-1}$ specific reverse solute flux was achieved with sulphonated TFC-FO membrane sample (50 wt\% SPES) under the FO mode using $2 \mathrm{M} \mathrm{NaCl}$ as the draw solution and deionised water as feed. Substrate sulphonation also considerably decreased the membrane structural parameter from $1096 \mu \mathrm{m}$ without sulphonation to $245 \mu \mathrm{m}$ at $50 \mathrm{wt} \%$ sulphonation. This study therefore shows that, besides surface morphology, the water flux of the FO membrane can also be enhanced by improving its substrate hydrophilic property.
\end{abstract}

Keywords: Forward osmosis, Sulphonated polymer, Sponge-like structure, Hydrophilic substrate

\section{Introduction}

The forward osmosis (FO) process has been emerging as an alternative technology for desalination, water treatment and power generation in recent years $[1,2]$. FO utilizes osmotic pressure for spontaneous water transport from the feed to the draw solution (DS) across a semi-permeable membrane. Compared to the pressure driven membrane technology such as 
reverse osmosis (RO), the FO process displays several merits that can potentially surpass the RO technology for certain applications especially where DS recovery and regeneration are not essential [3]. Practically, FO can be used as a pre-treatment or in hybrid units for desalination. Applying FO as a pre-treatment could minimize RO fouling and scaling while at the same time provides easier cleaning process for desalination or water treatment plant [4]. FO-nanofiltration or FO-pressure assisted osmosis hybrid systems have been proposed for fertigation by using fertilizer as DS [5-8]. Other potential and more practical applications of the FO process include juice and food concentration [9], protein and pharmaceutical enrichment [10], and power generation [11-14].

Lack of high performing membranes and DS that can be recycled effectively still remains as a major obstacle for the commercialisation of the FO technology $[2,5,15]$. The flat-sheet cellulose triacetate (CTA) FO membrane produced by Hydration Technologies Inc. (HTI, Albany, OR) is an FO membrane which is commercially available in the market produced at a large scale, although few more companies such as Oasys (Boston, MA) have started to make FO membranes but still in limited quantities. Regardless of its broad applications for the FO process, CTA FO membrane has relatively lower water flux than the few reported polyamide-based thin film composite (TFC) FO membranes [16]. Recently, attention has been drawn to the development of asymmetric flat sheet or hollow fibre FO membranes via phase inversion technique followed by interfacial polymerization [17, 18]. This TFC FO membrane has been inspired from the membrane fabrication approach that was originally developed for the RO process. It contains a very thin polyamide (PA) rejection layer and a polysulfone (Psf) support layer casted on a fabric support (usually made of non-woven polyethylene terephthalate or PET fabric) that gives additional mechanical strength to the membrane structure [19]. Chemically-modified TFC-RO membrane has also been investigated for the FO process and it has been found that the existing RO membrane can be used for all engineered osmosis applications [20]. However, the thick nonwoven support fabric and the hydrophobic Psf support layer results in high internal concentration polarization (ICP) effects that significantly reduces the water flux during the FO process [20]. Tiraferri et al. [21] and Yip et al. [17] suggested that an optimal FO membrane should consist of a very thin PA rejection layer on top of a highly porous finger-like structure substrate to decrease the ICP. Later studies have also demonstrated that membrane hydrophilicity plays a major role in inducing water flux across semi-permeable membranes [22]. A report by Wang et al. confirmed that FO performance can be further enhanced in TFC 
membranes by increasing membrane hydrophilicity [23]. Hence, in addition to the membrane support layer morphological structure, the other properties such as hydrophilicity has been manipulated to enhance the water flux in the FO process. However, hydrophilic polymers pose several disadvantages as membrane substrates, which include: (1) swelling that can negatively affect the membrane substrate strength as well as the stability of the PA rejection layer due to overstretched substrate, and; (2) interfacial polymerization formation inside the pores instead of just at the membrane top surface [24]. But on a positive note, increased substrate hydrophilicity can improve binding between the PA rejection layer and the substrate top surface compared to that of a substrate with a relatively hydrophobic nature and rough surface [23, 25]. Furthermore, interfacial polymerization has a significant effect on permeability regardless of substrate hydrophilicity [24]. Based on polymer solution and casting condition, each substrate can produce a different top skin layer and structural morphology. The physical and chemical properties of the substrate can therefore affect the PA layer formation resulting in different membrane performances [24].

Recently, sulphonated polyethersulfone (SPES) has been studied as a promising material in the proton exchange membrane fuel cell (PEMFC) applications and also for both RO and FO membranes to increase hydrophilicity and fouling resistance [26, 27]. It is also assumed that the sulphonation of the polymer materials can introduce not only the hydrophilic nature to the membrane substrate which enhances the water flux of the resultant FO membranes, but also may help change its membrane substrate morphology. Therefore, the objectives of this study are: (1) to investigate the influence of sulphonation of PES on the formation of substrate morphology and its mechanical strength, and (2) to investigate the effect of blended sulphonated materials as membrane substrates on FO performance. The synthesized SPES was directly blended with PES at specific ratios to prepare modified membranes.

\section{Material and methods}

\subsection{Chemicals}

Polyethersulfone (PES) granules (Mn: 55,000 - Good fellow, UK) and N-methyl-2pyrrolidone (NMP) (Sigma-Aldrich Pty. Ltd, Australia) were used for the fabrication of membrane substrates. M-phenylenediamine (MPD) with >99\% purity and trimesoyl chloride (TMC) with 98\% purity (Sigma-Aldrich Pty. Ltd, Australia) were used as received in this study for the interfacial polymerization process. N-hexane from Sigma-Aldrich with $>99.0 \%$ 
purity was utilized as the solvent for TMC. Sodium chloride $(\mathrm{NaCl})$ reagent grade supplied by Sigma-Aldrich, Australia was used to prepare DS and feed solution (FS). NaCl was dissolved in deionized (DI) water to prepare $0.5,1$ and $2 \mathrm{M}$ concentrations for use as DS with DI water as FS.

\subsection{Synthesis of SPES polymer}

The SPES polymer was synthesized following the method described by Xiao et al. [28]. The chemical structures of PES and SPES are illustrated in Figure 1. A mixture containing $772 \mathrm{~g}$ of dimethylsulfoxide, $257 \mathrm{~g}$ of toluene, $16.47 \mathrm{~g}$ (0.039 mol) of carbonylbis (2-fluorobenzene sulfonic acid) sodium salt, $99.98 \mathrm{~g}(0.390 \mathrm{~mol})$ of tetra methyl bis phenol $\mathrm{F}$ and $67.38 \mathrm{~g}$ $(0.488 \mathrm{~mol})$ of potassium carbonate were poured into a five-necked reactor equipped with a reflux condenser, a stirrer, a nitrogen-introducing tube and a thermometer. The reactor was heated to $140^{\circ} \mathrm{C}$ and maintained at this temperature for $12 \mathrm{~h}$ under constant stirring, then under nitrogen atmosphere for $8 \mathrm{~h}$ to remove water generated out of the system and then distilled toluene off for another $2 \mathrm{~h}$. The mixture was diluted with $180 \mathrm{~g}$ of NMP after it cooled down to room temperature. The mixture was discharged into $2000 \mathrm{~g}$ of methanol to precipitate the polymer solution followed by filtration and washing with water several times to remove residual methanol. The collected polymer was dried at $80^{\circ} \mathrm{C}$ for $10 \mathrm{~h}$ and then at $150^{\circ} \mathrm{C}$ for another $8 \mathrm{~h}$ under nitrogen atmosphere [28].

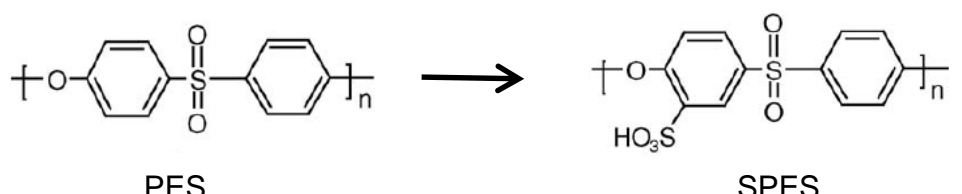

Figure 1: Chemical structure of PES and SPES synthesized in this study.

\subsection{Fabrication of flat-sheet TFC FO membranes}

\subsubsection{Fabrication of FO membrane substrates via phase inversion}

Casting solutions were prepared using certain amounts of PES and SPES as shown in Table 1. PES and SPES were dissolved in NMP and then stirred by a magnetic stirrer at room temperature for 24 hours. The polymer solutions were then degassed using digital bench top ultrasonic cleaner (Soniclean Pty Ltd, Australia) for $60 \mathrm{~min}$ and then stored in a desiccator for over 48 hours before casting. Casting was performed on a glass plate using a stainless steel film applicator (Sheen Instruments Ltd, UK) with an adjustable gate height fixed at $200 \mu \mathrm{m}$. 
The casted substrate was immersed immediately into a DI water bath to initiate phase inversion and it remained in the bath for 10 minutes. The resultant substrates were then kept in DI water before conducting the next stage on the formation of the PA rejection layer on top of the substrates.

Table 1: TFC-FO casting solution composition with different sulphonated polymer blend ratios.

\begin{tabular}{|l|ccc|c|}
\hline \multirow{2}{*}{ Membrane ID } & \multicolumn{3}{|c|}{ Casting solution composition } & Sulphonated polymer (\%) \\
\cline { 2 - 4 } & PES (wt\%) & NMP (wt\%) & SPES (wt\%) & \\
\hline TFC $_{1}$ & 12 & 88 & 0 & 0 \\
$\mathrm{TFC}_{2}$ & 8 & 88 & 4 & 25 \\
$\mathrm{TFC}_{3}$ & 6 & 88 & 6 & 50 \\
\hline
\end{tabular}

\subsubsection{Forming of rejection layer via interfacial polymerization}

The rejection layer on the top surface of the membrane substrates was formed by interfacial polymerization. The substrate was soaked first in $3.4 \mathrm{wt} \%$ aqueous MPD solution for 120 seconds and then with the help of an air knife the excess MPD solution was removed from the membrane top surface. Then n-hexane solution of $0.15 \mathrm{wt} \% \mathrm{TMC}$ was gently poured onto the top surface of substrates that were sealed in a frame for 60 seconds to form the ultrathin PA rejection layer.The sealed frame allows TMC solution to react with the MPD just on the top surface of the membrane. The resultant TFC-FO composite membrane was rinsed with DI water to remove the residual solution and then stored in DI water at $4{ }^{\circ} \mathrm{C}$ before characterization and performance tests.

\subsection{Membrane characterizations}

\subsubsection{Membrane substrate characterization}

Membrane substrate morphologies were studied using a high-resolution Schottky field emission scanning electron microscope (SEM, Zeiss Supra 55VP, Carl Zies AG, Germany). Membrane substrates were first dried in a vacuum condition at room temperature for $24 \mathrm{~h}$. To 
view the cross sections of the membranes, the samples were then flash-frozen in liquid nitrogen to preserve the pore structure then coated with a thin layer of carbon using Balzers Sputter coater (SCD 050, BAL-TEC, Germany) before SEM imaging.

The contact angles of the membranes were measured by a sessile drop method, using an optical tensiometer (Attension Theta Lite 100, Biolin Scientific, Finland). Membrane samples were first dried in vacuum at room temperature for $24 \mathrm{~h}$. Small DI water droplets $(5-7 \mu \mathrm{L})$ were applied onto a levelled membrane surface and profiles of the water drops were captured by a camera and the imaging software determined the contact angles. At least 3 measurements were obtained to get the average value of the contact angle. Membrane thickness was measured using a digital micrometre (293-330 Mitutoyo, Japan). Membrane porosity $(\varepsilon)$ was obtained by measuring the dry mass $\left(\mathrm{W}_{2}\right)$ and wet mass $\left(\mathrm{W}_{1}\right)$ of membrane samples according to the following equation $[29,30]$ :

$\varepsilon=\frac{(W 1-W 2) / \rho i}{\left[\frac{W 1-W 2}{\rho i}\right]+[W 2 / \rho m]} \times 100 \%$,

where $\rho_{i}$ and $\rho_{m}$ are the densities of wetting solvent and membrane, respectively.

The mechanical property of the membrane substrate was measured in terms of its tensile strength using LS1 tensile testing equipment (AMETEK, Lloyd instruments ltd, UK). The membranes substrates were cut into strips of $10 \mathrm{~mm}$ width and $25 \mathrm{~mm}$ length and the testing was conducted at the rate of $10 \mathrm{~mm} / \mathrm{min}$.

\subsubsection{TFC-FO membrane characterization}

The water permeability coefficient $(A)$ and salt rejection of the fabricated TFC membrane were determined based on the pure water fluxes obtained in the RO mode using the same membrane cell at different pressures ranging from 0-10 bar. Salt rejection $(R s)$ property of the TFC-FO membranes was determined by measuring the electrical conductivity of the permeate and the feed water $(200 \mathrm{ppm} \mathrm{NaCl})$ at 1 bar applied pressure. The salt permeability coefficient $(B)$ was then determined based on the following equation:

$$
\frac{1-R s}{R s}=\frac{B}{A(\Delta P-\Delta \pi)},
$$

where $\Delta \mathrm{P}$ is the applied hydraulic pressure and $\Delta \pi$ is the net osmotic pressure between the feed and the permeate. 


\subsection{Forward osmosis performance experiments}

FO experiments were conducted on a crossflow bench-scale FO experimental setup as reported in our previous study [31]. It consisted of two pumps (one each for DS and FS), each connected to the crossflow FO membrane cell. The volumetric flow rates of both sides were $200 \mathrm{~mL} / \mathrm{min}$. The FO water flux $\left(J_{w}\right)$ was determined by measuring the weight change of the feed tank using a digital mass balance connected to a data logging system. A heating/chilling unit maintained the DS and FS temperatures at $25^{\circ} \mathrm{C}$.

The membrane performances were evaluated under two different modes: (1) FO mode where the active layer faced the FS (AL-facing-FS), and (2) pressure retarded osmosis (PRO) mode where the active layer faced the DS (AL-facing-DS). For salt permeability, the reverse solute flux (RSF) was evaluated by observing the increase in the electrical conductivity (EC) of the DI feed water using a multimeter (CP-500L, ISTEK, Korea). RSF refers to the rate of reverse diffusion of draw solute mass $(\mathrm{g})$ through the membrane per unit area $\left(\mathrm{m}^{2}\right)$ and per unit time (h). For a given draw solute, the RSF increases when a higher DS concentrations are used during the FO process however, it also results in proportionately higher water flux. It has been observed that the ratio of reverse solute flux to water flux is constant for a particular draw solute for a specific membrane and this ratio is termed as the specific reverse solute flux (SRSF) and this data has been used in this study. A thermodynamic modelling software OLI Stream Analyser 3.2 (OLI Systems Inc., Morris Plains, NJ, US) was used to analyse the thermodynamic properties of the solutions such as viscosity, osmotic pressure, density and diffusion coefficient.

Based on the classical ICP model developed by Loeb et al, the water flux is represented by the following equations in the FO process (for FO and PRO modes) [32]:

$$
\begin{array}{ll}
J_{w}=\frac{1}{K_{D}}\left[\ln \frac{A \pi_{D, b}+B}{A \pi_{F m}+J w+B}\right] & \text { (AL-FS)-FO mode, } \\
J_{w}=\frac{1}{K_{D}}\left[\ln \frac{A \pi_{D, m}+J w+B}{A \pi_{F, b}+B}\right] & \text { (AL-DS)-PRO mode, }
\end{array}
$$

where $\pi_{F, b}$ and $\pi_{D, b}$ are the bulk osmotic pressure of the FS and DS, $\pi_{D m}$ and $\pi_{F m}$ are the osmotic pressures on membrane surfaces facing the DS and FS, respectively, $B$ is the salt permeability coefficient of the membrane, and $K_{D}$ is the solute resistivity for diffusion of draw solutes within the porous support defined as: 
$K_{D}=\frac{t \tau}{\varepsilon D}=\frac{S}{D}$

This equation shows the relationship among solute diffusion resistivity within the porous layer $K_{D}$, diffusivity $D$, membrane structural parameter $S$, membrane porosity $\varepsilon$, membrane thickness $t$ and membrane tortuosity $\tau$. This equation can be used to obtain the membrane structural parameter as well.

\section{Results and discussion}

\subsection{Effect of membrane substrates}

Sulphonated PES membrane substrate was synthesized by blending PES with the SPES and was compared with the pure PES substrate. The effect of sulphonation on the PES substrate formation by phase inversion was investigated in terms of its membrane morphology and changes in membrane hydrophilicity and mechanical strength. Figure 2 shows the SEM images of membrane substrates casted with different concentrations of sulphonated polymer as explained in Table 1. The height of the casting knife was adjusted to $200 \mu \mathrm{m}$ for all the substrate samples. However, after phase inversion, the thickness of these membrane substrates obtained was in the range of $65-80 \mu \mathrm{m}$. Previous studies confirm the effect of sulphonation on membrane thickness without clear indication [33, 34]. Many factors can affect membrane thickness during phase inversion, however, the thermodynamics of casting solution is considered to be the major contributing factor [35, 36]. Generally, the lower the thermodynamic instability of casting solution, the thinner the synthesized membrane will be. From SEM images (Figure 2) and thickness measurement, it was found that higher degree of sulphonation can cause sponge-like structure and thinner substrate. Due to the effect of larger swelling behaviour in the highly sulphonated samples, the membrane becomes thicker during actual test and under wet condition.

Figure 2 (a) shows the cross-section, top and bottom SEM images of the membrane substrate casted from pure PES (no sulphonation) indicating clearly the presence of a large number of finger-like pore structures which is in congruent with previous reported studies $[17,37]$. With sulphonation however, the membrane substrate formed loses its finger-like morphology although it was still faintly visible at $25 \mathrm{wt} \%$ as shown in Figure 2 (b). At higher sulphonation (50 wt \%), SPES substrates did not exhibit any finger like structures but rather 
a sponge-like structure with few macrovoids were observed as presented in Figure 2 (c). Membrane substrates formed during the phase inversion stage usually have few distinguished structures and morphologies [38]. Several pathways may occur for the original polymer solution during the phase inversion stage which can be explained using a ternary diagram [39]. Based on the ternary diagram, delayed demixing in the phase inversion can affect the substrate morphology. Adding sulphonated material would cause delayed demixing which results in a sponge-like substrate and significantly reduces macrovoid formation as the sulphonated material content increases. In other words, instantaneous demixing in nonsulphonated sample was expected to form a macrovoid structure.

Figure 2 also shows that while changes in membrane substrate cross section are obvious under different casting solution composition with a different degree of sulphonation, changes in the membrane top surface cannot be clearly visualised from SEM images.. However, previous studies showed that as the sulphonation concentration increases, membrane surface roughness decreases using atomic force microscopy (AFM) [33]. The top skin layer and the more porous sub layer can be formed by two separate pathways during the phase inversion stage. The top skin layer that forms on the surface of the porous membrane film is hypothesized to occur when the solvent diffusion from the membrane exceeds the nonsolvent infusion which can increase the polymer concentration on the top side and form a 

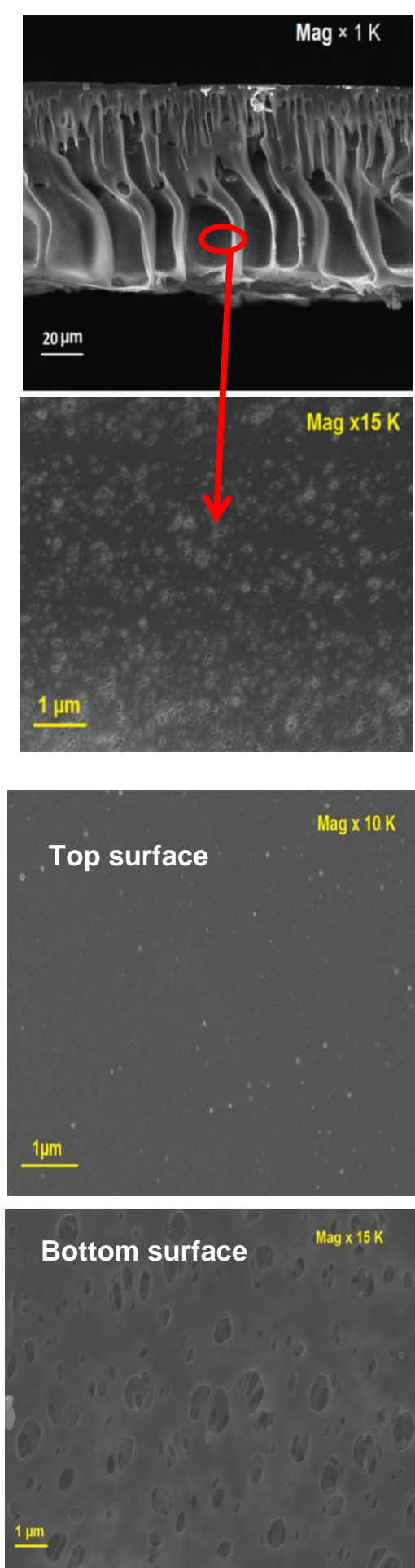

(a) PES
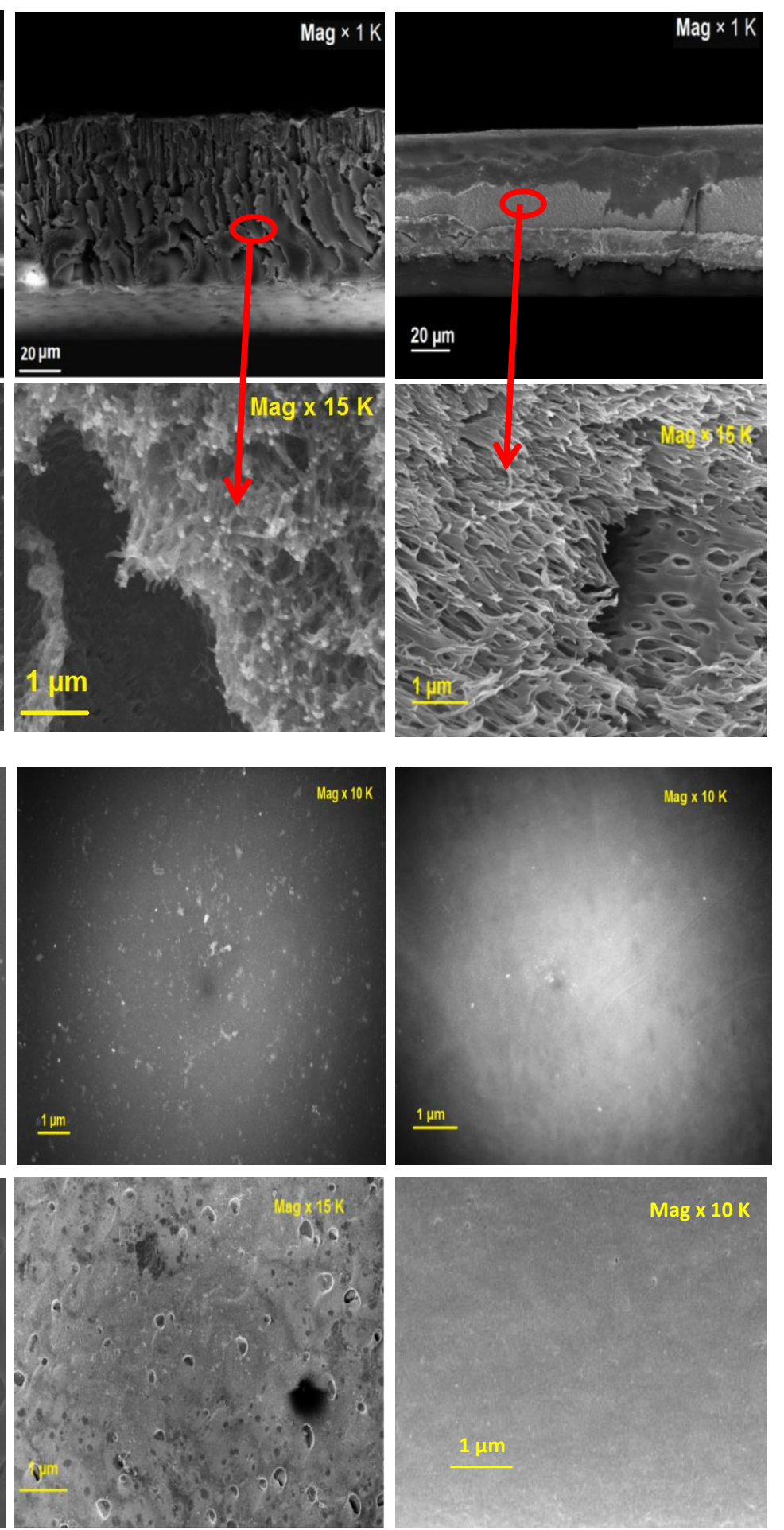

(b) SPES (25 wt $\%)$

(c) SPES (50 wt $\%)$

Figure 2: SEM images of membrane substrates with different blending ratios of sulphonated polymer for TFC fabrication: (a) no sulphonated polymer; (b) $25 \mathrm{wt} \%$ sulphonated material; (c) $50 \mathrm{wt} \%$ sulphonated material. All samples were fabricated under $12 \mathrm{wt} \%$ polymer concentration in NMP. 
slightly denser skin during phase inversion on the membrane top surface [40]. Therefore, delayed demixing due to increased sulphonated materials not only significantly changes the membrane substrate and morphology but also affects the surface properties such as roughness as previously reported. Furthermore, previous study shows that with an increased in sulphonated polymer, substrate become more porous with a relatively larger pore size [33]. The membrane bottom surface morphology in Figure 2 (a) shows traces of macrovoids in the substrate sample without sulphonation $\left(\mathrm{TFC}_{1}\right)$ and these macrovoids seem to decrease with sulphonation as shown in Figure 2 (b) for $\mathrm{TFC}_{2}(25 \mathrm{wt} \%)$. No such macrovoids can be found with the substrate sample $\mathrm{TFC}_{3}(50 \mathrm{wt} \%)$ as shown in Figure 2 (c).

Table 2 presents the membrane substrate characteristics at different degrees of sulphonation. The results confirm the hypothesis that the sulphonation of PES increases the hydrophilicity and the porosity of the membrane substrate. The contact angle of PES membrane substrate (without sulphonation) was $77.3^{\circ}$, while those of the sulphonated substrates showed relatively lower contact angles in the range of $20-25^{\circ}$ due to the increased hydrophilicity. Thus, these results show that the higher degree of hydrophilicity can be achieved by increasing the degree of sulphonation on the PES.

Table 2: Characteristics of membrane substrates at different sulphonation rates.

\begin{tabular}{|c|c|c|c|c|c|c|}
\hline \multirow{2}{*}{ Sample ID } & \multirow{2}{*}{$\begin{array}{c}\text { Thickness } \\
\qquad(\mu \mathrm{m})\end{array}$} & \multirow{2}{*}{$\begin{array}{c}\text { Porosity } \\
\text { (\%) }\end{array}$} & \multirow{2}{*}{$\begin{array}{l}\text { Contact } \\
\text { angle }\left(^{\circ}\right)\end{array}$} & \multicolumn{3}{|c|}{ Mechanical properties } \\
\hline & & & & $\begin{array}{l}\text { Tensile } \\
\text { strength (MPa) }\end{array}$ & $\begin{array}{l}\text { Modulus } \\
\text { (MPa) }\end{array}$ & $\begin{array}{l}\text { Elongation at } \\
\text { break (\%) }\end{array}$ \\
\hline $\mathrm{TFC}_{1-}(\mathrm{PES})$ & $80 \pm 3.0$ & $75 \pm 1$ & $77.3 \pm 1$ & 7.8 & 241 & 17.9 \\
\hline $\begin{array}{l}\mathrm{TFC}_{2-(\mathrm{SPES}-} \\
25 \%)\end{array}$ & $71 \pm 2.0$ & $77 \pm 1$ & $26 \pm 2$ & 3.6 & 72.1 & 36.2 \\
\hline $\begin{array}{l}\mathrm{TFC}_{3-} \text { (SPES- } \\
50 \%)\end{array}$ & $65 \pm 3.0$ & $79 \pm 3$ & $20 \pm 2$ & 1.1 & 12 & 43.3 \\
\hline
\end{tabular}

The mechanical strength of the fabricated membrane substrates is shown in Table 2 with different sulphonation ratios. With an increase in the sulphonation, the tensile strength and Young's modulus decrease while the elongation at break increases. From these results, it is 
clear that if the sulphonation is increased beyond $50 \mathrm{wt} \%$, the membrane substrate would have very poor mechanical strength.FO is not a pressure based membrane process and hence tensile strength of the polymeric support layer is not supposed to be a significant issue. It may however become an issue for FO application at larger-scale using membrane modules during which large flows are expected that could automatically build certain pressure during the operation. To strengthen the membrane tensile strength, the substrate can be supported using a backing fabric although this could compromise the water flux performance. Earlier studies have suggested that the reduction in tensile strength due to sulphonation may be related to two factors, namely: (1) the binding of strong polar sulfonic acid to the polymer chain may decrease the aggregative state and (2) the polymer matrix is expanded due to sulphonation thereby augmenting the polymer chain movements which give the polymer material more flexibility $[41,42]$.

Figure 3 shows the comparative FTIR spectra of PES and SPES (50 wt \%) membrane substrate samples to confirm the presence of $\mathrm{SO}_{3} \mathrm{H}$ group on the polymer chains. The symmetrical stretching vibrations of sulfonic acid groups and aromatic $\mathrm{SO}_{3} \mathrm{H}$ symmetric appear at $\sim 1180 \mathrm{~cm}^{-1}$ and $\sim 1025 \mathrm{~cm}^{-1}$, respectively [42, 43]. However, based on Figure 3, we could not detect the peaks distinctly probably because of near overlapping bands. The absorption peak at $3420 \mathrm{~cm}^{-1}$ is attributed to stretching vibrations linked to the hydroxyls of sulfonic acid groups, which confirm the presence of sulfonic acid groups in the SPES membrane samples.

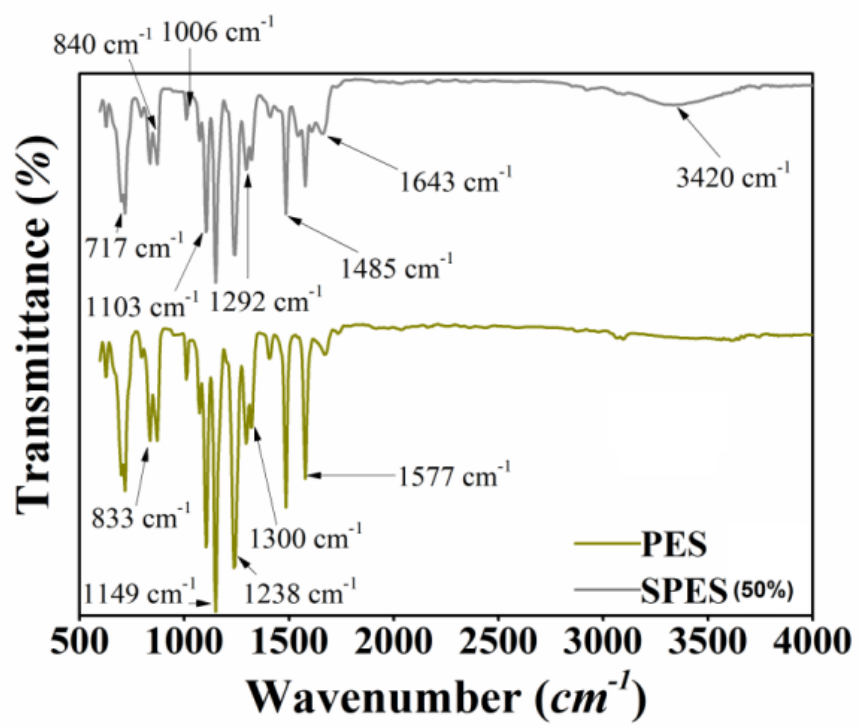

Figure 3: FTIR spectra of membrane substrate sample for PES and SPES 50 wt \%. 


\subsection{Characterization of TFC-FO membranes}

TFC-FO membranes were prepared via interfacial polymerisation on the top surface of prepared membrane substrates. Table 3 summarizes the TFC-FO membrane transport properties and their structural parameters. The pure water permeability coefficient $(A)$ of the TFC-FO membranes increases with the increase in sulphonation rates. For example, the $A$ values of $1.1 \mathrm{Lm}^{-2} \mathrm{~h}^{-1} \mathrm{bar}^{-1}$ ( $\mathrm{LMH} \mathrm{bar}{ }^{-1}$ ) for the $\mathrm{TFC}_{1}$ (substrate without sulphonation) increased to 2.1 $\mathrm{LMH} \mathrm{bar}^{-1}$ and $2.9 \mathrm{LMH} \mathrm{bar}^{-1}$ for $\mathrm{TFC}_{2}$ (25 wt\% sulphonation) and $\mathrm{TFC}_{3}$ (50 wt\% sulphonation), respectively.

The salt permeability coefficient $(B)$ also slightly increased with the degree of sulphonation. However, regardless of the degree of substrate sulphonation, all the TFC membranes showed a reasonable salt rejection of $93.3 \%, 91.3 \%$, and $91.1 \%$ for $\mathrm{TFC}_{1}, \mathrm{TFC}_{2}$ and $\mathrm{TFC}_{3}$, respectively.

The membrane $\mathrm{A}$ and $\mathrm{B}$ parameters are intrinsic membrane properties related to the top rejection layer independent of the substrate properties. The increase in the $A$ and $B$ values with the degree of sulphonation is therefore probably related to the characteristics of the top skin layer of the membrane substrate formed during the phase inversion stage that likely affected the formation of the PA rejection layer. It was discussed earlier under Section 3.1 that, at higher degree of sulphonation, a much smoother top skin surface is generally formed that likely provided more suitable conditions for the formation of a PA rejection layer with uniform thickness. At no sulphonation or at lower degree of sulphonation, the top skin layer of the substrate could be rougher which may likely result in the formation of non-uniform thickness with a much thicker PA layer (average) thereby reducing the membrane permeability.

Lower structural parameter is preferable for any membrane-based osmotic processes. The membrane structural parameter is related to the degree of ICP and membrane properties such as thickness and porosity. The structural parameters ( $S$ value) of the three TFC-FO membranes shown in Table 3 indicate that the $\mathrm{S}$ values of the TFC-FO membrane decreased with an increase in the degree of sulphonation. The $S$ value for $\mathrm{TFC}_{1}$ was $1096 \mu \mathrm{m}$ which 
decreased to $335 \mu \mathrm{m}$ and $245 \mu \mathrm{m}$ for $\mathrm{TFC}_{2}$ and $\mathrm{TFC}_{3}$, respectively with sulphonation. $\mathrm{TFC}_{2}$ and $\mathrm{TFC}_{3}$ had lower thickness and higher porosities than $\mathrm{TFC}_{1}$.

Generally, higher degree of sulphonation resulted in more porous substrate with lowers structural parameter. Most previous works indicate that the membrane porosity and water permeability are related to the polymer concentration used to cast the membrane substrate and additives such as pore formers [44]; however, the results in Table 2 show that sulphonation makes the membrane substrate more porous for the sample prepared at similar polymer concentrations (all the three membrane substrate samples were fabricated with 12 wt $\%$ polymer concentration). Furthermore, the permeability of the TFC active layer increases with the increase in the sulphonation degree although both the TFC membranes with $25 \mathrm{wt}$ $\%$ and $50 \mathrm{wt} \%$ sulphonation were composed of similar polymer concentrations as the $\mathrm{TFC}_{1}$ without sulphonation.

Membranes with various degree of sulphonation have different chemical properties and top surface pore size and topologies which consequently affect the interfacial polymerization and PA layer formation [33]. Although it is hard to differentiate the effect of sulphonation on interfacial polymerization through SEM images however, the performance in terms of water flux and salt permeability can greatly help in interpreting the rejection layer properties under increased sulphonation rate. For example, the $A$ value for $\mathrm{TFC}_{1}$ (without substrate sulphonation) was 1.1 $\mathrm{LMH} \mathrm{bar}^{-1}$ which increased to $2.1 \mathrm{LMH} \mathrm{bar}^{-1}$ for $\mathrm{TFC}_{2}(25 \mathrm{wt} \%$ ) and 2.9 $\mathrm{LMH} \mathrm{bar}^{-1}$ for $\mathrm{TFC}_{3}(50 \mathrm{wt} \%$ ) membrane samples. However, this also correspondingly led to slight decrease in the salt rejection or increase in the $B$ value of the sulphonated TFC membranes compared to un-sulphonated $\mathrm{TFC}_{1}$ membrane. The higher water permeability and higher salt permeability for $\mathrm{TFC}_{3}$ compared to $\mathrm{TFC}_{2}$ also indicate that at higher sulphonation degree, it results in the formation of thinner PA rejection layer due to smoother substrates. 
Table 3. Transport properties and structural parameters of fabricated membrane samples.

\begin{tabular}{|l|l|l|c|c|c|}
\hline \multirow{2}{*}{ Sample ID } & \multicolumn{2}{|c|}{${ }^{\mathbf{a}}$ Water permeability $(A)$} & ${ }^{\mathbf{b}}$ Salt permeability $B\left(10^{-8} \mathrm{~m} / \mathrm{s}\right)$ & NaCl rejection $(\%)$ & ${ }^{\mathrm{c}} S$ value \\
\cline { 2 - 3 } & $\mathrm{L} / \mathrm{m}^{2} \mathrm{~h}^{-1} \mathrm{bar}^{-1}$ & $\times^{10-12} \mathrm{~m} / \mathrm{s} \mathrm{Pa}$ & & & 1096 \\
\hline TFC-1 & $1.1 \pm 0.15$ & $3.1 \pm 0.5$ & $2.6 \pm 0.1 .3$ & 93.2 & 335 \\
TFC-2 & $2.1 \pm 0.26$ & $5.1 \pm 0.5$ & $4.1 \pm 0.1 .3$ & 91.3 & 245 \\
TFC-3 & $2.9 \pm 0.25$ & $8.1 \pm 0.5$ & $5.1 \pm 0.1 .3$ & 91.1 & \\
\hline
\end{tabular}

a Evaluated in the RO testing mode over an applied pressure range of 1 bar with DI water as feed water .

b Evaluated in the RO testing mode over an applied pressure range of 1 bar for a feed water containing $200 \mathrm{ppm} \mathrm{NaCl}$.

${ }^{\text {c }}$ Evaluated on experiments under the $\mathrm{FO}$ mode using $2 \mathrm{M} \mathrm{NaCl}$ as the draw solution with DI water as feed water.

\subsection{Performance of TFC-FO membranes}

The performances of synthesized TFC-FO membranes with different sulphonation degree were assessed under both FO and PRO modes of operations using $0.5-2.0 \mathrm{M} \mathrm{NaCl}$ as DS and DI water as feed. Their comparative performances in terms of water fluxes and reverse solute fluxes for the TFC membrane samples under the FO and PRO modes of membrane orientation at various $\mathrm{NaCl}$ DS concentrations with DI FS are presented in Figure 4.

As expected, the water flux presented in Figure 4 (a) increases with an increase in DS concentration for all the TFC membrane samples due to a greater driving force generated by higher DS concentration. 


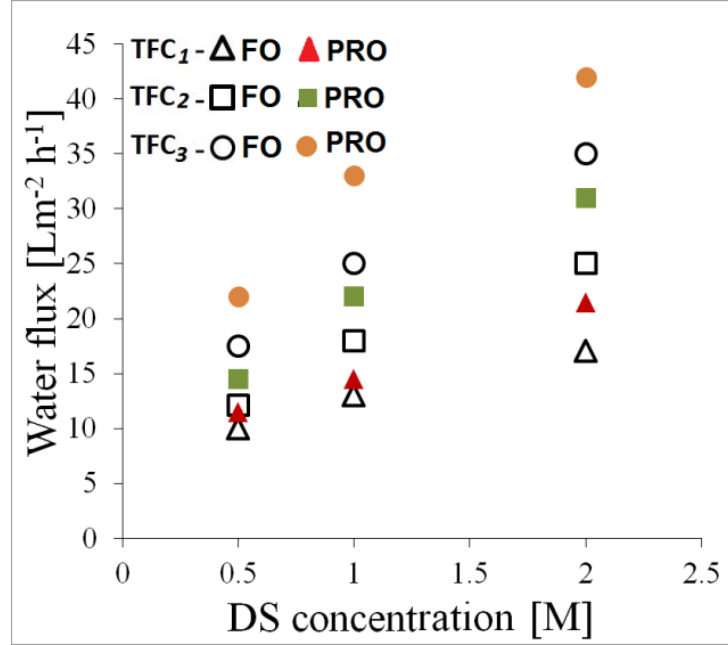

(a)

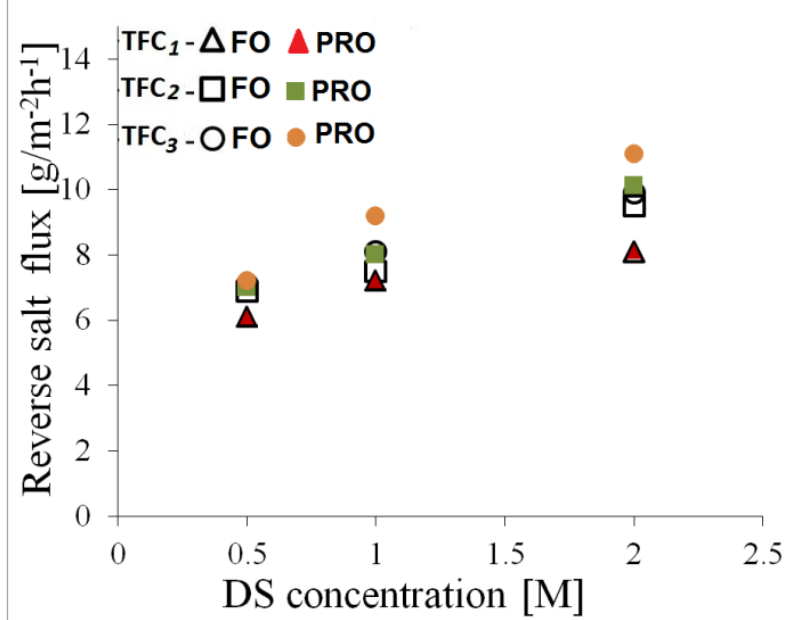

(b)

Figure 4: Performance comparison of fabricated membranes in terms of water flux and reverse solute flux under $\mathrm{FO}$ and $\mathrm{PRO}$ with various $\mathrm{NaCl}$ concentrations as DS and DI water as feed. (a) performance of membrane samples in terms of water flux, (b) performance of membrane samples in terms of reverse solute flux. ( $\mathrm{TFC}_{1}$ contains 0 wt $\%$ sulphonated concentration in the membrane substrate while $\mathrm{TFC}_{2}$ and $\mathrm{TFC}_{3}$ have $25 \mathrm{wt} \%$ and $50 \mathrm{wt} \%$ sulphonated concentration in the membrane substrates, respectively).

As shown in Figure 4 (a), the water flux performances of the TFC FO membrane were improved significantly with the increase in the degree of sulphonation. Table 4 shows the summary of water fluxes using $2 \mathrm{M} \mathrm{NaCl}$ as DS and DI water as FS under two different modes of membrane orientations. For example, the water flux of the $\mathrm{TFC}_{3} \mathrm{FO}$ membrane at 2 $\mathrm{M} \mathrm{NaCl}$ was 35.1 LMH compared to $25 \mathrm{LMH}$ for $\mathrm{TFC}_{2}$ and $17.12 \mathrm{LMH}$ for $\mathrm{TFC}_{1}$. These results clearly show the benefits of sulphonation of the PES substrate on FO water flux. Similar improvement in water flux for the sulphonated TFC membranes was also observed under the PRO mode of membrane orientation. For example, the water flux for $\mathrm{TFC}_{1} \mathrm{FO}$ membrane at $2 \mathrm{M} \mathrm{NaCl} \mathrm{DS}$ and DI as FS under the PRO mode was $21.5 \mathrm{LMH}$ which increased to 31.0 $\mathrm{LMH}$ and 42.1 $\mathrm{LMH}$ for $\mathrm{TFC}_{2}$ and $\mathrm{TFC}_{3}$, respectively. These water fluxes under the PRO mode of membrane orientation are only about $20-26 \%$ higher than water fluxes under the FO mode of membrane orientation. This is slightly lower than significant differences in the water fluxes observed between FO and PRO modes of membrane orientation with PRO mode generally producing twice or more water fluxes compared to those under FO modes of membrane orientations with the PA based TFC FO membranes [31, 
45, 46]. This lower water flux differences between the FO and PRO modes of membrane orientation indicate that, the extent of dilutive ICP in the FO mode is less significant probably further supporting the positive influence of substrate sulphonation. As pointed out earlier, although sulphonation increases the water flux by improving its substrate structure and hydrophilicity, however, the mechanical strength (tensile strength) of TFC membrane decreases with the increase of the degree of sulphonation (Table 2).

Table 4: Performance of fabricated TFC-FO membrane using $2 \mathrm{M} \mathrm{NaCl}$ as DS and DI as FS under FO and PRO modes.

\begin{tabular}{lll}
\hline Membrane & FO mode & PRO mode
\end{tabular}

ID

\begin{tabular}{lccc|ccc}
\cline { 2 - 5 } & $\begin{array}{l}\text { Water } \\
(\mathrm{LMH})\end{array}$ & $\begin{array}{l}\text { flux } \\
\left(\mathrm{g} \mathrm{m}^{-2} \mathrm{~h}^{-1}\right)\end{array}$ & $\begin{array}{l}\text { SRSF } \\
\left(\mathrm{gL}^{-1}\right)\end{array}$ & $\begin{array}{l}\text { Water flux } \\
(\mathrm{LMH})\end{array}$ & $\mathrm{RSF}\left(\mathrm{g} \mathrm{m}^{-2} \mathrm{~h}^{-1}\right)$ & $\mathrm{SRSF}\left(\mathrm{gL}^{-1}\right)$ \\
\hline $\mathrm{TFC}_{1}$ & 17 & 7.5 & 0.44 & 21.5 & 8.1 & 0.37 \\
$\mathrm{TFC}_{2}$ & 25 & 9.5 & 0.38 & 31 & 10 & 0.32 \\
$\mathrm{TFC}_{3}$ & 35.1 & 9.9 & 0.28 & -42.1 & 11.1 & 0.26 \\
\hline
\end{tabular}

Based on the water flux performances under the FO and PRO modes of membrane orientations presented in Figure 4 and Tables 3 and 4, it is clear that, substrate sulphonation can significantly help improve the performances of the TFC FO membranes in terms of water flux. This increase in water flux is likely due to two main reasons: (1) change in the membrane support morphology and, (2) the improvement in its hydrophilic property. However, a closer observation on the membrane cross section morphologies for the three TFC FO membrane samples (Figure 2) reveals interesting results. $\mathrm{TFC}_{3}$ membrane possesses a denser sponge-like support layer structure compared to finger-like support structures for $\mathrm{TFC}_{2}$ and $\mathrm{TFC}_{1}$ and yet $\mathrm{TFC}_{3}$ resulted in the best performance in terms of water flux. This result therefore indicates that, the performances of the FO membranes can be improved by not only having a finger-like membrane substrate structure morphology but also by improving the hydrophilicity of the sponge-like membrane substrate such as through optimum sulphonation. The main advantage of the sponge-like substrate compared to the finger-like substrate could be in the form of better resistance to membrane compaction. 
Membrane with higher number of macro voids in the sub layer tends to undergo compaction when subjected to hydraulic pressure adversely affecting the membrane performance. During compaction, the walls of the pores could come closer making the membrane substrate more denser resulting in reduction in pore size water permeability of the substrate $[47,48]$.

RSF is another important performance parameter in assessing the performance of the FO membranes. It measures the extent of draw solute that reversely diffuses through the FO membrane during the osmotic process. A high RSF of the FO membrane results in significant loss of DS towards the feed water complicating the concentrate management, membrane fouling/scaling and water flux performance beside the economic loss. Figure 4 (b) and Table 4 show the RSF of three fabricated TFC FO membrane samples under the FO and PRO modes of membrane orientations. Although the water flux increases with the increase in the degree of membrane substrate sulphonation however, this also correspondingly increased the RSF of the TFC FO membranes. For example, the RSF of the $\mathrm{TFC}_{1}$ membrane (at $2 \mathrm{M}$ $\mathrm{NaCl}$ as DS and DI as FS under FO mode) was $7.5 \mathrm{~g} \mathrm{~m}^{-2} \mathrm{~h}^{-1}$ which then increased to $9.5 \mathrm{~g} \mathrm{~m}^{-}$ ${ }^{2} \mathrm{~h}^{-1}$ and $9.9 \mathrm{~g} \mathrm{~m}^{-2} \mathrm{~h}^{-1}$ with sulphonation for $\mathrm{TFC}_{2}$ and $\mathrm{TFC}_{3}$, respectively. Likewise under the PRO mode of membrane orientation using similar DS-FS condition, the RSF for the $\mathrm{TFC}_{1}$ membrane sample was $8.1 \mathrm{~g} \mathrm{~m}^{-2} \mathrm{~h}^{-1}$ which increased to $10 \mathrm{~g} \mathrm{~m}^{-2} \mathrm{~h}^{-1}$ and $11.1 \mathrm{~g} \mathrm{~m}^{-2} \mathrm{~h}^{-1}$ for TFC 2 and $\mathrm{TFC}_{3} \mathrm{FO}$ membranes, respectively. Although the RSF under the PRO mode of membrane orientation is higher than under the FO mode however, the ratio of RSF generally termed as the specific RSF (SRSF) (ratio of RSF to the water flux) is fairly constant irrespective of the membrane orientations or the DS concentrations [49]. The SRSF decreased slightly with the increase of sulphonation. Table 5 presents the comparative performances of three fabricated TFC FO membranes in this study with other works reported in the literature. It is clear from these comparative data that, sulphonated TFC FO membranes fabricated in this study have comparable performances in terms of water flux and SRSF. 
Table 5: Performance comparison of flat sheet TFC-FO membranes in FO mode.

\begin{tabular}{|c|c|c|c|c|c|c|}
\hline Membrane types & Materials & $\begin{array}{l}\text { Water flux } \\
\left(\mathrm{Lm}^{-2} \mathrm{~h}^{-1}\right)\end{array}$ & $\begin{array}{l}\text { Specific reverse } \\
\text { salt flux }\left(\mathrm{gL}^{-1}\right)\end{array}$ & $\begin{array}{c}\mathrm{DS} \\
(\mathrm{M}) \\
\mathrm{NaCl}\end{array}$ & FS & References \\
\hline SPES TFC-FO & PES & $18 / 25$ & $0.4 / 0.32$ & $1 / 2$ & DI & $\begin{array}{c}\text { Present } \\
\text { work }\end{array}$ \\
\hline SPES TFC-FO & PES & $26 / 35$ & $0.36 / 0.28$ & $1 / 2$ & DI & $\begin{array}{c}\text { Present } \\
\text { work }\end{array}$ \\
\hline $\begin{array}{l}\text { TFC flat-sheet } \\
\text { (HTI) }\end{array}$ & Psf & 13 & 0.81 & 2 & DI & {$[50]$} \\
\hline $\begin{array}{l}\text { TFC flat-sheet } \\
\text { membrane }\end{array}$ & Psf & 12 & 0.4 & 1 & $\begin{array}{l}10 \mathrm{mM} \\
\mathrm{NaCl}\end{array}$ & {$[51]$} \\
\hline $\begin{array}{l}\text { TFC flat-sheet } \\
\text { membrane }\end{array}$ & Psf & 20.5 & -- & 1 & DI & [21] \\
\hline $\begin{array}{l}\text { TFC flat-sheet } \\
\text { membrane }\end{array}$ & Psf & 15.1 & - & 1 & DI & [17] \\
\hline SPSf TFC FO & Psf & 26 & 0.3 & 2 & DI & [23] \\
\hline SPSf TFC FO & Psf & 18 & 0.2 & 1 & DI & {$[23]$} \\
\hline
\end{tabular}

\section{Conclusions}

The effect of sulphonation on the PES substrate to synthesize TFC-FO membranes was studied through substrate characterisation such as morphology, wettability, tensile strength and TFC membrane performances. The following summary is drawn from this work:

- Sulphonation of PES substrate changes the substrate morphology from finger-like to a sponge-like substrate at higher degree of sulphonation, increases substrate hydrophilicity, improves membrane permeability coefficient ( $A$ value), and decreases membrane structural parameter ( $S$ value) although it resulted in increased salt permeability (B value), salt rejection and tensile strength. 
- The performances of the TFC-FO membranes in terms of water flux increased while the specific reverse solute flux decreased with the increase in the degree of sulphonation. The TFC FO membrane at $50 \mathrm{wt} \%$ sulphonation showed the best performance with water fluxes of $35.1 \mathrm{~L} \mathrm{~m}^{-2} \mathrm{~h}^{-1}$ (FO mode) and $42.1 \mathrm{~L} \mathrm{~m}^{-2} \mathrm{~h}^{-1}$ (PRO mode) using $2 \mathrm{M} \mathrm{NaCl}$ as DS and DI water as FS compared to $17.0 \mathrm{~L} \mathrm{~m}^{-2} \mathrm{~h}^{-1}$ (FO mode) and 21.5 $\mathrm{L} \mathrm{m}^{-2} \mathrm{~h}^{-1}$ (PRO mode) for un-sulphonated TFC FO membrane under the same operating conditions.

\section{Acknowledgments}

This study was supported by the Australian postgraduate award (APA), the Australian Research Council (ARC) Discovery Projects (DP140100835), and the National Centre of Excellence in Desalination Australia (NCEDA), which is funded by the Australian Government through the Water for the Future initiative.

\section{References}

[1] T.-S. Chung, S. Zhang, K.Y. Wang, J. Su, M.M. Ling, Forward osmosis processes: yesterday, today and tomorrow, Desalination, 287 (2012) 78-81.

[2] T.Y. Cath, A.E. Childress, M. Elimelech, Forward osmosis: Principles, applications, and recent developments, Journal of Membrane Science, 281 (2006) 70-87.

[3] L. Liu, M. Wang, D. Wang, C. Gao, Current Patents of Forward Osmosis Membrane Process, Recent Patents on Chemical Engineering, 2 (2009) 76-82.

[4] V. Yangali-Quintanilla, Z. Li, R. Valladares, Q. Li, G. Amy, Indirect desalination of Red Sea water with forward osmosis and low pressure reverse osmosis for water reuse, Desalination, 280 (2011) 160-166.

[5] S. Phuntsho, H.K. Shon, S. Hong, S. Lee, S. Vigneswaran, A novel low energy fertilizer driven forward osmosis desalination for direct fertigation: evaluating the performance of fertilizer draw solutions, Journal of Membrane Science, 375 (2011) 172-181.

[6] S. Phuntsho, S. Hong, M. Elimelech, H.K. Shon, Forward osmosis desalination of brackish groundwater: Meeting water quality requirements for fertigation by integrating nanofiltration, Journal of Membrane Science, 436 (2013) 1-15. 
[7] S. Phuntsho, S. Hong, M. Elimelech, H.K. Shon, Fertiliser-Drawn Forward Osmosis Desalination for Fertigation, in: Forward Osmosis, American Society of Civil Engineers 2015, pp. 395-426.

[8] S. Sahebi, S. Phuntsho, J. Eun Kim, S. Hong, H. Kyong Shon, Pressure assisted fertiliser drawn osmosis process to enhance final dilution of the fertiliser draw solution beyond osmotic equilibrium, Journal of Membrane Science, 481 (2015) 63-72.

[9] E.M. Garcia-Castello, J.R. McCutcheon, M. Elimelech, Performance evaluation of sucrose concentration using forward osmosis, Journal of Membrane Science, 338 (2009) 6166.

[10] M.M. Ling, T.-S. Chung, Novel dual-stage FO system for sustainable protein enrichment using nanoparticles as intermediate draw solutes, Journal of Membrane Science, 372 (2011) 201-209.

[11] K.L. Lee, R.W. Baker, H.K. Lonsdale, Membranes for power generation by pressureretarded osmosis, Journal of Membrane Science, 8 (1981) 141-171.

[12] K.-V. Peinemann, K. Gerstandt, S.E. Skilhagen, T. Thorsen, T. Holt, Membranes for Power Generation by Pressure Retarded Osmosis, in: Membranes for Energy Conversion, Wiley-VCH Verlag GmbH \& Co. KGaA, 2008, pp. 263-273.

[13] A. Achilli, T.Y. Cath, A.E. Childress, Power generation with pressure retarded osmosis: An experimental and theoretical investigation, Journal of Membrane Science, 343 (2009) 4252.

[14] S. Loeb, Large-scale power production by pressure-retarded osmosis, using river water and sea water passing through spiral modules, Desalination, 143 (2002) 115-122.

[15] J.R. McCutcheon, R.L. McGinnis, M. Elimelech, A novel ammonia-carbon dioxide forward (direct) osmosis desalination process, Desalination, 174 (2005) 1-11.

[16] T.Y. Cath, A.E. Childress, M. Elimelech, Forward osmosis: principles, applications, and recent developments, Journal of Membrane Science, 281 (2006) 70-87.

[17] N.Y. Yip, A. Tiraferri, W.A. Phillip, J.D. Schiffman, M. Elimelech, High Performance Thin-Film Composite Forward Osmosis Membrane, Environmental Science \& Technology, 44 (2010) 3812-3818.

[18] R. Wang, L. Shi, C.Y. Tang, S. Chou, C. Qiu, A.G. Fane, Characterization of novel forward osmosis hollow fiber membranes, Journal of Membrane Science, 355 (2010) 158167. 
[19] J.E. Cadotte, Interfacially synthesized reverse osmosis membrane, in, Google Patents, 1981.

[20] J.T. Arena, B. McCloskey, B.D. Freeman, J.R. McCutcheon, Surface modification of thin film composite membrane support layers with polydopamine: Enabling use of reverse osmosis membranes in pressure retarded osmosis, Journal of Membrane Science, 375 (2011) $55-62$.

[21] A. Tiraferri, N.Y. Yip, W.A. Phillip, J.D. Schiffman, M. Elimelech, Relating performance of thin-film composite forward osmosis membranes to support layer formation and structure, Journal of Membrane Science, 367 (2011) 340-352.

[22] J.R. McCutcheon, M. Elimelech, Influence of membrane support layer hydrophobicity on water flux in osmotically driven membrane processes, Journal of Membrane Science, 318 (2008) 458-466.

[23] K.Y. Wang, T.-S. Chung, G. Amy, Developing thin-film-composite forward osmosis membranes on the PES/SPSf substrate through interfacial polymerization, AIChE Journal, 58 (2012) 770-781.

[24] A.K. Ghosh, E.M.V. Hoek, Impacts of support membrane structure and chemistry on polyamide-polysulfone interfacial composite membranes, Journal of Membrane Science, 336 (2009) 140-148.

[25] A.K. Ghosh, B.-H. Jeong, X. Huang, E.M.V. Hoek, Impacts of reaction and curing conditions on polyamide composite reverse osmosis membrane properties, Journal of Membrane Science, 311 (2008) 34-45.

[26] J.F. Blanco, Q.T. Nguyen, P. Schaetzel, Novel hydrophilic membrane materials: sulfonated polyethersulfone Cardo, Journal of Membrane Science, 186 (2001) 267-279.

[27] S. Wen, C. Gong, W.-C. Tsen, Y.-C. Shu, F.-C. Tsai, Sulfonated poly (ether sulfone)(SPES)/boron phosphate (BPO 4) composite membranes for high-temperature proton-exchange membrane fuel cells, International journal of hydrogen energy, 34 (2009) 8982-8991.

[28] Y. Li, W.B. Krantz, T.S. Chung, A novel primer to prevent nanoparticle agglomeration in mixed matrix membranes, AIChE Journal, 53 (2007) 2470-2475.

[29] P. Sukitpaneenit, T.-S. Chung, Molecular elucidation of morphology and mechanical properties of PVDF hollow fiber membranes from aspects of phase inversion, crystallization and rheology, Journal of Membrane Science, 340 (2009) 192-205. 
[30] X. Li, Y. Wang, X. Lu, C. Xiao, Morphology changes of polyvinylidene fluoride membrane under different phase separation mechanisms, Journal of Membrane Science, 320 (2008) 477-482.

[31] S. Phuntsho, S. Sahebi, T. Majeed, F. Lotfi, J.E. Kim, H.K. Shon, Assessing the major factors affecting the performances of forward osmosis and its implications on the desalination process, Chemical Engineering Journal, 231 (2013) 484-496.

[32] S. Loeb, L. Titelman, E. Korngold, J. Freiman, Effect of porous support fabric on osmosis through a Loeb-Sourirajan type asymmetric membrane, Journal of Membrane Science, 129 (1997) 243-249.

[33] N. Widjojo, T.-S. Chung, M. Weber, C. Maletzko, V. Warzelhan, The role of sulphonated polymer and macrovoid-free structure in the support layer for thin-film composite (TFC) forward osmosis (FO) membranes, Journal of Membrane Science, 383 (2011) 214-223.

[34] N. Widjojo, T.-S. Chung, M. Weber, C. Maletzko, V. Warzelhan, A sulfonated polyphenylenesulfone (sPPSU) as the supporting substrate in thin film composite (TFC) membranes with enhanced performance for forward osmosis (FO), Chemical Engineering Journal, 220 (2013) 15-23.

[35] M. Sadrzadeh, S. Bhattacharjee, Rational design of phase inversion membranes by tailoring thermodynamics and kinetics of casting solution using polymer additives, Journal of Membrane Science, 441 (2013) 31-44.

[36] H.F. Mark, J.I. Kroschwitz, Encyclopedia of polymer science and engineering, Wiley, 1989.

[37] A. Tiraferri, N.Y. Yip, W.A. Phillip, J.D. Schiffman, M. Elimelech, Relating performance of thin-film composite forward osmosis membranes to support layer formation and structure, Journal of Membrane Science, 367 (2011) 340-352.

[38] H.F. Mark, Encyclopedia of polymer science and technology; Plastics, resins, rubbers, fibers. Vol. 8. Keratin to modacrylic fibers, (1968).

[39] J.G. Wijmans, J. Kant, M.H.V. Mulder, C.A. Smolders, Phase separation phenomena in solutions of polysulfone in mixtures of a solvent and a nonsolvent: relationship with membrane formation, Polymer, 26 (1985) 1539-1545.

[40] J. Wijmans, J. Kant, M. Mulder, C. Smolders, Phase separation phenomena in solutions of polysulfone in mixtures of a solvent and a nonsolvent: relationship with membrane formation, Polymer, 26 (1985) 1539-1545. 
[41] B. Smitha, S. Sridhar, A. Khan, Synthesis and characterization of proton conducting polymer membranes for fuel cells, Journal of Membrane Science, 225 (2003) 63-76.

[42] R. Guan, H. Zou, D. Lu, C. Gong, Y. Liu, Polyethersulfone sulfonated by chlorosulfonic acid and its membrane characteristics, European Polymer Journal, 41 (2005) 1554-1560.

[43] I. Kim, J. Choi, T. Tak, Sulfonated polyethersulfone by heterogeneous method and its membrane performances, Journal of Applied Polymer Science, 74 (1999) 2046-2055.

[44] R. McGinnis, G. McGurgan, Forward osmosis membranes, in, Google Patents, 2013.

[45] T. Majeed, S. Phuntsho, S. Sahebi, J.E. Kim, J.K. Yoon, K. Kim, H.K. Shon, Influence of the process parameters on hollow fiber-forward osmosis membrane performances, Desalination and Water Treatment, 54 (2015) 817-828.

[46] S.M. Mamisaheby, S.P. Phuntsho, H.S. Shon, F.L. Lotfi, J.K. Kim, Factors Affecting the Performances of Forward Osmosis Desalination Process, Procedia Engineering, 44 (2012) $1449-1451$.

[47] B. Chakrabarty, A.K. Ghoshal, M.K. Purkait, Preparation, characterization and performance studies of polysulfone membranes using PVP as an additive, Journal of Membrane Science, 315 (2008) 36-47.

[48] X. Li, S. Zhang, F. Fu, T.-S. Chung, Deformation and reinforcement of thin-film composite (TFC) polyamide-imide (PAI) membranes for osmotic power generation, Journal of Membrane Science, 434 (2013) 204-217.

[49] T.Y. Cath, M. Elimelech, J.R. McCutcheon, R.L. McGinnis, A. Achilli, D. Anastasio, A.R. Brady, A.E. Childress, I.V. Farr, N.T. Hancock, Standard methodology for evaluating membrane performance in osmotically driven membrane processes, Desalination, 312 (2013) 31-38.

[50] W.A. Phillip, J.S. Yong, M. Elimelech, Reverse draw solute permeation in forward osmosis: modeling and experiments, Environmental Science \& Technology, 44 (2010) 51705176.

[51] J. Wei, C. Qiu, C.Y. Tang, R. Wang, A.G. Fane, Synthesis and characterization of flatsheet thin film composite forward osmosis membranes, Journal of Membrane Science, 372 (2011) 292-302. 